\title{
Cell, tissue and gene products with marketing authorization in 2018 worldwide
}

\author{
NATIVIDAD CUENDE ${ }^{1,2}$, JOHN E.J. RASKO ${ }^{3,4,5,6}$, MICKEY B.C. $\mathrm{KOH}^{7,8}$, \\ MASSIMO DOMINICI ${ }^{9,10}$ \& LAERTIS IKONOMOU ${ }^{11,12}$
}

\begin{abstract}
${ }^{1}$ Andalusian Initiative for Advanced Therapies, Funta de Andalucía, Seville, Spain, ${ }^{2}$ Andalusian Transplant Coordination, Servicio Andaluz de Salud, Seville, Spain, ${ }^{3}$ Sydney Medical School, University of Sydney, Sydney, Australia, ${ }^{4}$ Gene and Stem Cell Therapy Program, Centenary Institute, Sydney, Australia, ${ }^{5}$ Department of Cell and Molecular Therapies, Royal Prince Alfred Hospital, New South Wales, Australia, ${ }^{6}$ International Society for Cell \& Gene Therapy (ISCT) President, ${ }^{7}$ Department of Haematology, St George's Hospital and Medical School, London, UK, ${ }^{8}$ Blood Services Group, Health Sciences Authority, Singapore, ${ }^{9}$ Division of Oncology, Laboratory of Cellular Therapy, University of Modena $\mathcal{E}$ Reggio Emilia, Modena, Italy, ${ }^{10}$ Chair, ISCT Presidential Task Force on the Use of Unproven Cellular Therapies, ${ }^{11}$ The Pulmonary Center, Boston University School of Medicine, Boston, Massachusetts, USA, and ${ }^{12}$ Center for Regenerative Medicine of Boston University and Boston Medical Center, Boston, Massachusetts, USA
\end{abstract}

\begin{abstract}
Cell and gene therapies (CGTs) are progressively entering into clinical practice in different parts of the world. The International Society for Cell \& Gene Therapy (ISCT), a global scientific society, has been committed since 1992 to supporting and developing knowledge on clinical applications of CGTs. Considering the number of products that have been progressively approved and, in some cases, withdrawn in recent years, the ISCT would like to present a brief annual report on CGTs with marketing authorization (MA) in different regions. This article reflects the dynamic momentum around authorized CGTs coinciding with the parallel increase of unproven approaches where cells are delivered without appropriate and rigorous scientific and regulatory assessment and authorization. This is intended to be a living document with a yearly update linked to a dedicated section of the ISCT website for faster adjustments. The aim is to ultimately inform, by periodic snapshots, the scientific community, healthcare stakeholders and patient associations on authorized CGT products as a way to increase communication around the approved therapeutic approaches charged with heightened expectations.
\end{abstract}

\section{Introduction}

The International Society for Cell \& Gene Therapy (ISCT) is committed to translating cellular therapy into safe and effective treatments to improve patients' lives while minimizing and balancing risks for patients. Being aware that many unproven or insufficiently proven cell-based treatments are commercially available for hopeful individuals seeking cures or health improvement for a variety of conditions, the ISCT created the ISCT Presidential Task Force (PTF) on the Use of Unproven Cellular Therapies (UCT) in 2014. The PTFUCT strives to characterize unproven cellular interventions and promote safe and effective practices worldwide $[1,2]$.

In line with the above goals, the PTF-UCT has launched several initiatives including providing updated information on approved cellular therapies. For a list of PTF-UCT-authored resources visit http:/www.celltherapysociety.org/page/UCT. In this document the PTF-UCT has summarized cell, tissue and gene medicinal products authorized for commercialization by regions/countries, to help patients seeking safe and effective treatments. We have not included any products that are categorized as medical devices, even if they are cell-based. If a patient lives in one of the regions/countries

Correspondence: Natividad Cuende, MD, MPH, PhD, Andalusian Initiative for Advanced Therapies/Iniciativa Andaluza en Terapias Avanzadas, Junta de Andalucía, C/ Algodón s/n (Esq. Avd. Hytasa), 41006 Sevilla, Spain. Correspondence: Laertis Ikonomou, PhD, Center for Regenerative Medicine of Boston University and Boston Medical Center, 670 Albany St Biosquare III, Boston, MA 02118, USA. E-mail: natividad.cuende.sspa@juntadeandalucia.es, laertis@bu.edu 
included in the document and a healthcare professional or a business is offering a cell-based treatment not listed, they should ask whether they are going to receive the treatment as part of a clinical trial. If not, the ISCT recommends asking for more information about the "regulatory status" of the treatment they are going to receive to make an informed decision.

\section{Definitions and principles}

Human cell- or tissue-based products are highly heterogeneous and regulatory authorities will always apply their rulings on a case-by-case basis. Nevertheless, at present, most of the cell- and tissue-based products are considered biological medicinal products in those countries with more developed regulatory structures. The development of safe and effective "proven" cell therapies requires testing these medicinal products according to some general principles [3]. Before administration into humans, both biological activity and toxicity of the investigational medicinal product must be tested in relevant animal model(s). Researchers must then seek approval of an institutional review board (IRB) for all centers involved in the clinical trial as well as an authorization from the national regulatory agencies of the countries where patients will be recruited, irrespective of their nationalities. The sponsor's duties also include ensuring: (i) that there is an insurance policy in place to cover any liability, (ii) that recruitment of subjects is done after appropriate informed consent and (iii) that medicinal product batches for release conform to specifications. If the regulatory bodies determine that quality, safety and efficacy of a cell- or tissue-based medicinal product are sufficiently established through successful clinical phases (clinical trial phase 1,2 and 3), then the next step is to apply for marketing authorization (MA). After that, the company that holds the MA can commercialize the medicinal product in the countries in which the product has been granted MA. In some cases, MA is provisional and post-marketing surveillance studies are required. Of note, some countries permit exceptions to this authorization rule depending on the nature of the medicinal product, be it industrial or otherwise. In any case, the use of a medicinal product has to be supervised by a regulatory body.

\section{Identified cell and gene therapies with MA}

We have identified and listed cell and gene therapies (CGTs) with MA based on available information, considering as a source of trustworthy information the regulatory body web resources, official press release by the interested companies or other source of data as indicated in Tables I-X where countries/ regions are listed in alphabetical order. The list has been updated as of September 15, 2018, unless otherwise specified.

In Figure 1, we present the distribution of authorized CGT products by region. In addition, we have listed (Table XI) the CGT approaches that have received a Regenerative Medicine Advanced Therapy (RMAT) designation by the United States Food and Drug Administration (USFDA) [4] but have not been approved as of September 2018. In Figure 2, we have categorized CGT products with MA worldwide in three different ways, namely, by product, therapy and disease type. Finally, in Figure 3 we present CGT products according to the year in which they received MA.

Several products are currently available in different regions but have the same MA holder (YESCARTA, KYMRIAH, IMLYGIC, RMS Ossron/OSSGROW and Chondron/CARTIGROW). These products are taken into account only once in Figures 2 and 3, leading to a total number of 44 unique products.

\section{Discussion and conclusions}

The goal of this article is to provide a quick reference for anyone interested in a snapshot, to be updated annually, of the CGT landscape worldwide. This list may not be exhaustive and additional CGT products

Table I. List of cell/tissue/gene products with MA in Australia by TGA.

\begin{tabular}{|c|c|c|c|c|c|}
\hline Name (MA holder) & $\begin{array}{l}\text { Product description and } \\
\text { indication }(\mathrm{s})\end{array}$ & Product category & Date of MA & Current status & $\begin{array}{l}\text { Additional } \\
\text { information }\end{array}$ \\
\hline $\begin{array}{l}\text { Chondrocytes - T - } \\
\text { Ortho-ACI (Orthocell } \\
\text { Pty Ltd) }\end{array}$ & $\begin{array}{l}\text { Autologous cultured } \\
\text { chondrocytes for use } \\
\text { in treatment of carti- } \\
\text { lage lesions associated } \\
\text { with the knee, patella } \\
\text { and ankle }\end{array}$ & Cell therapy product & 26-Mar-2017 & Still in market & $\frac{\text { Click here for }}{\underline{\text { link to TGA }}}$ \\
\hline
\end{tabular}

TGA, Therapeutic Goods Administration. 
Table II. List of cell/tissue/gene products with MA in Canada by Health Canada (March 2018).

\begin{tabular}{|c|c|c|c|c|c|}
\hline Name (MA holder) & $\begin{array}{l}\text { Product description and } \\
\text { indication(s) }\end{array}$ & Product category & Date of MA & Current status & $\begin{array}{l}\text { Additional } \\
\text { information }\end{array}$ \\
\hline $\begin{array}{l}\text { KYMRIAH (NOVARTIS } \\
\text { PHARMACEUTI- } \\
\text { CALS CANADA INC) }\end{array}$ & $\begin{array}{l}\text { CD19-directed genetically } \\
\text { modified autologous T-cell } \\
\text { immunotherapy indicated for } \\
\text { the treatment of pediatric } \\
\text { and young adult patients } \\
3 \text {-25 y with B-cell ALL who } \\
\text { are refractory, have relapsed } \\
\text { after allogeneic SCT or are } \\
\text { otherwise ineligible for SCT, } \\
\text { or have experienced second } \\
\text { or later relapse and for the } \\
\text { treatment of adult patients } \\
\text { with relapsed or refractory } \\
\text { large B-cell lymphoma after } \\
\text { two or more lines of systemic } \\
\text { therapy including DLBCL } \\
\text { not otherwise specified, high- } \\
\text { grade B-cell lymphoma and } \\
\text { DLBCL arising from follicu- } \\
\text { lar lymphoma. }\end{array}$ & $\begin{array}{l}\text { Gene therapy } \\
\text { product }\end{array}$ & 05-Sep-2018 & In market & $\frac{\frac{\text { Click here for }}{\text { link to Health }}}{\frac{\text { Canada }}{\text { website }}}$ \\
\hline $\begin{array}{l}\text { Prochymal (MESO- } \\
\text { BLAST INTERNA- } \\
\text { TIONAL SARL) }\end{array}$ & $\begin{array}{l}\text { Allogeneic ex vivo-cultured } \\
\text { adult human mesenchymal } \\
\text { stromal cells for the manage- } \\
\text { ment of aGvHD in pediatric } \\
\text { patients }\end{array}$ & $\begin{array}{l}\text { Cell therapy } \\
\text { product }\end{array}$ & 02-May-2015 & $\begin{array}{l}\text { The product was } \\
\text { never marketed } \\
\text { in Canada }\end{array}$ & $\frac{\frac{\text { Click here for }}{\text { link to Health }}}{\frac{\text { Canada }}{\underline{\text { website }}}}$ \\
\hline
\end{tabular}

ALL, acute lymphoblastic leukemia; SCT, stem cell transplantation; DLBCL, diffuse large B-cell lymphoma; aGVHD, acute graft-versushost disease.

Table III. List of cell/tissue/gene products with MA in China by CSFDA.

\begin{tabular}{|c|c|c|c|c|c|}
\hline Name (MA holder) & $\begin{array}{l}\text { Product description and } \\
\text { indication }(\mathrm{s})\end{array}$ & Product category & Date of MA & Current status & $\begin{array}{l}\text { Additional } \\
\text { information }\end{array}$ \\
\hline $\begin{array}{l}\text { Gendicine (Shenzhen SiBiono } \\
\text { GeneTech Co. Ltd.) }\end{array}$ & $\begin{array}{l}\text { Recombinant adenovirus } \\
\text { expressing p53 for treat- } \\
\text { ment of head and neck } \\
\text { squamous cell carcinoma }\end{array}$ & Gene therapy product & Oct-2003 & Still in market & Click here \\
\hline
\end{tabular}

CSFDA, Chinese Food and Drug Administation.

with MA will be included in future updates. To our knowledge, no cell/tissue/gene products have been authorized for marketing in Brazil, Hong Kong, Israel, Malaysia, Singapore and Taiwan as of September 2018.

We have identified 44 unique products, 37 of them are cell and tissue therapies (84\%) and mainly autologous (55\%) (Figure 2). As far as targeted diseases are concerned, more than one third of the products are intended for the treatment of oncological or hematologic diseases.

As shown in Figure 3, the number of products with MA has increased in recent years. For example, those authorized from 2015 to September 2018 represent $45 \%$. Unfortunately, there has been a parallel increase in the number of businesses offering unproven and unlicensed cell-based interventions $[5,6]$.
Even though the distribution of authorized CGTs shows important differences among countries or regions, it is not our intention to debate the complex financial, societal and scientific reasons behind these differences or the impact of different regulatory systems on the number of marketed products. As members of the ISCT PTF-UCT, our main objective is to help patients make informed decisions before receiving a cell or gene treatment so that they can avoid being exposed to unproven and unlicensed cell interventions. For that purpose, we aim to provide a reliable, up-to-date resource where patients or professionals can check whether a cell or gene therapy has been approved by a regulatory/medicine agency.

As mentioned before, the ISCT recommends asking for information about the "regulatory status" of the treatment patients are going to receive to make 
Table IV. List of Cell/Tissue/Gene Products with MA in the European Union by EMA.

\begin{tabular}{|c|c|c|c|c|c|}
\hline Name (MA holder) & $\begin{array}{l}\text { Product description and } \\
\text { indication }(\mathrm{s})\end{array}$ & ATMP & Date of MA & Current status & $\begin{array}{l}\text { Additional } \\
\text { information }\end{array}$ \\
\hline $\begin{array}{c}\text { YESCARTA (Kite } \\
\text { Pharma EU B.V.) }\end{array}$ & $\begin{array}{l}\text { CD19-directed genetically modi- } \\
\text { fied autologous T cell immuno- } \\
\text { therapy indicated for the } \\
\text { treatment of adult patients with } \\
\text { relapsed or refractory DLBCL } \\
\text { and PMBCL, after two or more } \\
\text { lines of systemic therapy }\end{array}$ & GTMP & 23-Aug-2018 & $\begin{array}{l}\text { Details of MA condi- } \\
\text { tions not displayed at } \\
\text { EMA website as of } \\
\text { 31-Aug-2018 }\end{array}$ & $\frac{\frac{\text { Click here for }}{\text { link to EMA }}}{\underline{\text { website }}}$ \\
\hline $\begin{array}{l}\text { KYMRIAH (Novartis } \\
\text { Europharm } \\
\text { Limited) }\end{array}$ & $\begin{array}{l}\text { CD19-directed genetically modi- } \\
\text { fied autologous T-cell immuno- } \\
\text { therapy indicated for the } \\
\text { treatment of pediatric and young } \\
\text { adult patients up to } 25 \text { y of age } \\
\text { with B-cell ALL that is refrac- } \\
\text { tory, in relapse post-transplanta- } \\
\text { tion or in second or later relapse, } \\
\text { and for the treatment of adult } \\
\text { patients with relapsed or refrac- } \\
\text { tory DLBCL after two or more } \\
\text { lines of systemic therapy }\end{array}$ & GTMP & 27-Aug-2018 & $\begin{array}{l}\text { Details of MA condi- } \\
\text { tions not displayed at } \\
\text { EMA website as of } \\
\text { 31-Aug-2018 }\end{array}$ & $\frac{\frac{\text { Click here for }}{\text { link to EMA }}}{\underline{\text { website }}}$ \\
\hline $\begin{array}{l}\text { ALOFISEL (Takeda } \\
\text { Pharma A/S) }\end{array}$ & $\begin{array}{l}\text { Expanded allogeneic adipose stem } \\
\text { cells as a suspension for injection } \\
\text { for the treatment of complex } \\
\text { perianal fistulas in patients with } \\
\text { Crohn's disease }\end{array}$ & SCTMP & 27-Mar-2018 & $\begin{array}{l}\text { The company will com- } \\
\text { plete a study to con- } \\
\text { tinue to collect } \\
\text { information on the } \\
\text { effectiveness and } \\
\text { safety }\end{array}$ & $\frac{\frac{\text { Click here for }}{\text { link to EMA }}}{\underline{\text { website }}}$ \\
\hline $\begin{array}{l}\text { SPHEROX (CO. } \\
\text { DON AG) }\end{array}$ & $\begin{array}{l}\text { Spheroids of human autologous } \\
\text { matrix-associated chondrocytes } \\
\text { for knee-repairing cartilage } \\
\text { defects }\end{array}$ & TEP & 10-Jul-2017 & $\begin{array}{l}\text { MA under several obli- } \\
\text { gations (post-authori- } \\
\text { zation long-term } \\
\text { efficacy and safety } \\
\text { study, prospective pro- } \\
\text { cess validation study } \\
\text { and re-validation of } \\
\text { the potency assay) }\end{array}$ & $\frac{\frac{\text { Click here for }}{\text { link to EMA }}}{\underline{\text { website }}}$ \\
\hline $\begin{array}{l}\text { ZALMOXIS } \\
\quad(\text { MolMed SpA) }\end{array}$ & $\begin{array}{l}\text { Donor's T lymphocytes genetically } \\
\text { modified with a suicide gene as a } \\
\text { control mechanism for GVHD } \\
\text { after haploidentical bone mar- } \\
\text { row transplantation }\end{array}$ & GTMP & 18-Aug-2016 & $\begin{array}{l}\text { Granted MA under } \\
\text { conditional approval }\end{array}$ & $\frac{\frac{\text { Click here for }}{\text { link to EMA }}}{\underline{\text { website }}}$ \\
\hline $\begin{array}{l}\text { STRIMVELIS (GSK } \\
\text { Trading Services } \\
\text { Limited) }\end{array}$ & $\begin{array}{l}\text { Autologous CD34+ cells trans- } \\
\text { duced with a retroviral vector } \\
\text { that encodes for the human } \\
\text { ADA cDNA sequence for severe } \\
\text { combined immunodeficiency } \\
\text { due to ADA deficiency }\end{array}$ & GTMP & 26-May-2016 & $\begin{array}{l}\text { Granted MA under } \\
\text { additional monitoring } \\
\text { until } 2037\end{array}$ & $\frac{\frac{\text { Click here for }}{\text { link to EMA }}}{\underline{\text { website }}}$ \\
\hline $\begin{array}{l}\text { IMLYGIC (Amgen } \\
\text { Europe B.V.) }\end{array}$ & $\begin{array}{l}\text { Oncolytic immunotherapy derived } \\
\text { from a herpex simplex virus-1 } \\
\text { genetically engineered to infect } \\
\text { and replicate within melanoma } \\
\text { cells and to produce GM-CSF } \\
\text { for unresectable melanoma }\end{array}$ & GTMP & 16-Dec-2015 & $\begin{array}{l}\text { Granted MA under } \\
\text { additional monitoring }\end{array}$ & $\frac{\frac{\text { Click here for }}{\text { link to EMA }}}{\underline{\text { website }}}$ \\
\hline $\begin{array}{l}\text { HOLOCLAR (Chiesi } \\
\text { Farmaceutici S.p.A.) }\end{array}$ & $\begin{array}{l}\text { Ex vivo-expanded autologous } \\
\text { human corneal epithelial cells } \\
\text { containing stem cells for severe } \\
\text { limbal stem cell deficiency }\end{array}$ & SCTMP & 17-Feb-2015 & $\begin{array}{l}\text { Granted MA under } \\
\text { conditional approval }\end{array}$ & $\frac{\frac{\text { Click here for }}{\text { link to EMA }}}{\underline{\text { website }}}$ \\
\hline
\end{tabular}

EMA, European Medicines Agency; ATMP, Advanced Therapy Medicinal Product; PMBCL, primary mediastinal large B-cell lymphoma; ADA, Adenosine deaminase; cDNA, complementary DNA; TEP, Tissue Engineered Product; GTMP, Gene Therapy Medicinal Product; SCTMP, Somatic Cell Therapy Medicinal Product; EC, European Commission. 
Table V. List of cell/tissue/gene products with MA withdrawn or suspended in the European Union by EMA.

\begin{tabular}{|c|c|c|c|c|c|}
\hline Name (MA holder) & $\begin{array}{l}\text { Product description and } \\
\text { indication }(\mathrm{s})\end{array}$ & ATMP & Date of MA & Current status & $\begin{array}{l}\text { Additional } \\
\text { information }\end{array}$ \\
\hline $\begin{array}{r}\text { PROVENGE } \\
\text { (Dendreon) }\end{array}$ & $\begin{array}{l}\text { Autologous peripheral-blood } \\
\text { mononuclear cells activated } \\
\text { with prostatic acid phospha- } \\
\text { tase granulocyte-macrophage } \\
\text { colony-stimulating factor for } \\
\text { metastatic prostate cancer }\end{array}$ & SCTMP & 6-Sep-2013 & $\begin{array}{l}\text { Granted MA under } \\
\text { additional monitoring. } \\
\text { Withdrawn: company } \\
\text { announced bank- } \\
\text { ruptcy in } 2015\end{array}$ & $\frac{\frac{\text { Click here for }}{\text { link to EMA }}}{\underline{\text { website }}}$ \\
\hline $\begin{array}{l}\text { MACI (Aastrom } \\
\text { Biosciences, Inc.) }\end{array}$ & $\begin{array}{l}\text { Matrix applied characterized } \\
\text { autologous cultured chon- } \\
\text { drocytes for repairing knee } \\
\text { cartilage defects }\end{array}$ & TEP & 27-Jun-2013 & $\begin{array}{l}\text { Granted MA under } \\
\text { additional monitoring. } \\
\text { MA suspended: } 25- \\
\text { Sep-2014 }\end{array}$ & $\frac{\frac{\text { Click here for }}{\text { link to EMA }}}{\underline{\text { website }}}$ \\
\hline $\begin{array}{l}\text { GLYBERA (uniQure } \\
\text { biopharma BV) }\end{array}$ & $\begin{array}{l}\text { Alipogene tiparvovec (human } \\
\text { lipoprotein lipase gene vari- } \\
\text { ant in a adeno-associated } \\
\text { viral vector) for adult patients } \\
\text { with familiar lipoprotein } \\
\text { lipase deficiency }\end{array}$ & GTMP & $25-O c t-2012$ & $\begin{array}{l}\text { Granted MA under } \\
\text { additional monitoring. } \\
\text { Withdrawn: MA } \\
\text { expired on 25-Oct- } \\
\text { 2017. The company } \\
\text { did not apply for } \\
\text { renewal due to the } \\
\text { lack of demand }\end{array}$ & $\frac{\frac{\text { Click here for }}{\text { link to EMA }}}{\underline{\text { website }}}$ \\
\hline $\begin{array}{l}\text { CHONDROCELECT } \\
\text { (TiGenix NV) }\end{array}$ & $\begin{array}{l}\text { Characterized viable autolo- } \\
\text { gous cartilage cells expanded } \\
\text { ex vivo for repairing knee car- } \\
\text { tilage defects }\end{array}$ & TEP & 5-Oct-2009 & $\begin{array}{l}\text { The product was reim- } \\
\text { bursed in } 3 \text { countries. } \\
\text { Withdrawn: } 30-\text { Nov- } \\
2016 \text {. Requested by } \\
\text { the company for com- } \\
\text { mercial reasons }\end{array}$ & $\frac{\frac{\text { Click here for }}{\text { link to EMA }}}{\underline{\text { website }}}$ \\
\hline
\end{tabular}

Table VI. List of cell/tissue/gene products with MA in India by DCGI.

\begin{tabular}{|c|c|c|c|c|c|}
\hline Name (MA holder) & $\begin{array}{l}\text { Product description and } \\
\text { indication }(\mathrm{s})\end{array}$ & Product category & Date of MA & Current status & $\begin{array}{l}\text { Additional } \\
\text { information }\end{array}$ \\
\hline $\begin{array}{l}\text { CARTIGROW }^{\mathrm{TM}} \\
\text { (Chondron ACI) } \\
\text { (RMS Regrow) }\end{array}$ & $\begin{array}{l}\text { Autologous cultured carti- } \\
\text { lage cells for treatment of } \\
\text { articular cartilage defects }\end{array}$ & $\begin{array}{c}\text { Cell therapy } \\
\text { product }\end{array}$ & Apr-2017 & $\begin{array}{l}\text { Conditional approval, post- } \\
\text { market surveillance study } \\
\text { required ( } 50 \text { subjects) }\end{array}$ & Click here \\
\hline $\begin{array}{l}\text { OSSGROW } \\
\text { (Ossron ABI) (RMS } \\
\text { Regrow) }\end{array}$ & $\begin{array}{l}\text { Autologous cultured osteo- } \\
\text { blasts for avascular necro- } \\
\text { sis of hip }\end{array}$ & $\begin{array}{c}\text { Cell therapy } \\
\text { product }\end{array}$ & Apr-2017 & $\begin{array}{l}\text { Conditional approval, post- } \\
\text { market surveillance study } \\
\text { required ( } 50 \text { subjects) }\end{array}$ & \\
\hline $\begin{array}{l}\text { APCEDEN (APAC } \\
\text { Biotech) }\end{array}$ & $\begin{array}{l}\text { Autologous monocyte- } \\
\text { derived mature dendritic } \\
\text { cells for treatment of } \\
\text { prostate, ovarian, colorec- } \\
\text { tal and non-small cell } \\
\text { lung carcinoma }\end{array}$ & $\begin{array}{l}\text { Cell therapy } \\
\text { product }\end{array}$ & Mar-2017 & $\begin{array}{l}\text { Conditional approval, post- } \\
\text { market surveillance study } \\
\text { required }\end{array}$ & Click here \\
\hline $\begin{array}{c}\text { Stempeucel }^{\circledR} \text { (Stem- } \\
\text { peutics Research) }\end{array}$ & $\begin{array}{l}\text { Ex vivo-cultured adult } \\
\text { allogeneic mesenchymal } \\
\text { stromal cells for treat- } \\
\text { ment of critical limb } \\
\text { ischemia due to Throm- } \\
\text { boangiitis Obliterans } \\
\text { (Buerger's disease) }\end{array}$ & $\begin{array}{l}\text { Cell therapy } \\
\text { product }\end{array}$ & May-2016 & $\begin{array}{l}\text { In market, limited release ( } 200 \\
\text { patients on a cost recovery } \\
\text { basis), post-market surveil- } \\
\text { lance study required }\end{array}$ & $\underline{\text { Click here }}$ \\
\hline
\end{tabular}

DCGI, Drug Controller General of India.

an informed decision. This is particularly relevant for patients living in one of the regions/countries included in the document who seek safe and effective treatments, should a healthcare professional or a business offer a CGT that is neither listed nor part of a clinical trial.

\section{Acknowledgments}

Authors are grateful to the entire PTF-UCT for the fruitful suggestions and to the ISCT Head Office in Vancouver, in particular to Iulia Dude and Sophie Bockhold, for the support in 
Table VII. List of cell/tissue/gene products with MA in Japan by PMDA.

\begin{tabular}{|c|c|c|c|c|c|}
\hline Name (MA holder) & $\begin{array}{l}\text { Product description and } \\
\text { indication }(\mathrm{s})\end{array}$ & Product category & Date of MA & Current status & $\begin{array}{l}\text { Additional information } \\
\text { (In Japanese) }\end{array}$ \\
\hline $\begin{array}{l}\text { Temcell HS (JCR } \\
\text { Pharmaceuticals } \\
\text { Co. Ltd.) }\end{array}$ & $\begin{array}{l}\text { Allogeneic mesenchymal } \\
\text { stromal cells for treat- } \\
\text { ment of aGVHD }\end{array}$ & $\begin{array}{l}\text { Cell therapy } \\
\text { product }\end{array}$ & Sep-2015 & In market & $\frac{\text { Click here for link to }}{\underline{\text { PMDA website }}}$ \\
\hline $\begin{array}{c}\text { HeartSheet (Terumo } \\
\text { Corporation, Ltd.) }\end{array}$ & $\begin{array}{l}\text { Autologous skeletal myoblast } \\
\text { sheet product for the treat- } \\
\text { ment of severe heart failure }\end{array}$ & $\begin{array}{l}\text { Tissue engi- } \\
\text { neered product }\end{array}$ & Sep-2015 & $\begin{array}{l}\text { Conditional } \\
\text { approval }\end{array}$ & $\frac{\text { Click here for link to }}{\text { PMDA website }}$ \\
\hline JACC (J-TEC) & $\begin{array}{l}\text { Autologous cultured } \\
\text { cartilage }\end{array}$ & $\begin{array}{l}\text { Tissue engi- } \\
\text { neered product }\end{array}$ & Jul-2012 & $\begin{array}{l}\text { Still in market, } \\
\text { previous autho- } \\
\text { rization was as } \\
\text { medical device }\end{array}$ & $\frac{\text { Click here for link to }}{\text { PMDA website }}$ \\
\hline JACE (J-TEC) & $\begin{array}{l}\text { Autologous cultured epi- } \\
\text { dermis for treatment of } \\
\text { severe burns }\end{array}$ & $\begin{array}{l}\text { Tissue engi- } \\
\text { neered product }\end{array}$ & Oct-2007 & $\begin{array}{l}\text { Still in market, } \\
\text { previous autho- } \\
\text { rization was as } \\
\text { medical device }\end{array}$ & $\frac{\text { Click here for link to }}{\underline{\text { PMDA website }}}$ \\
\hline
\end{tabular}

PMDA, Pharmaceuticals and Medical Devices Agency.

Table VIII. List of cell/tissue/gene products with MA in New Zealand by MEDSAFE.

\begin{tabular}{|c|c|c|c|c|c|}
\hline Name (MA holder) & $\begin{array}{l}\text { Product description and } \\
\text { indication(s) }\end{array}$ & Product category & Date of MA & Current status & $\begin{array}{l}\text { Additional } \\
\text { information }\end{array}$ \\
\hline $\begin{array}{l}\text { Prochymal (Osiris Ther- } \\
\text { apeutics Incorporated) }\end{array}$ & $\begin{array}{l}\text { Allogeneic ex vivo-cultured } \\
\text { adult human mesenchymal } \\
\text { stromal cells indicated for the } \\
\text { rescue of patients NLT } 6 \text { mo } \\
\text { to } 17 \text { y of age with aGVHD, } \\
\text { refractory to treatment with } \\
\text { systemic corticosteroid ther- } \\
\text { apy or other immunosup- } \\
\text { pressive agents }\end{array}$ & $\begin{array}{l}\text { Cell therapy } \\
\text { product }\end{array}$ & 14-Jun-2012 & Approval lapsed & $\frac{\frac{\text { Click here for }}{\text { link to MED }}}{\underline{\text { SAFE website }}}$ \\
\hline
\end{tabular}

MEDSAFE, Medicines and Medical Devices Safety Authority; NLT, Not Lower Than.

Table IX. List of cell/tissue/gene products with MA in South Korea by MFDS.

\begin{tabular}{|c|c|c|c|c|c|}
\hline Name (MA holder) & $\begin{array}{l}\text { Product description and } \\
\text { indication }(\mathrm{s})\end{array}$ & Product category & Date of MA & Current status & $\begin{array}{l}\text { Additional } \\
\text { information }\end{array}$ \\
\hline $\begin{array}{l}\text { KeraHeal-Allo }^{\mathrm{TM}} \\
\text { (Biosolution }^{\text {Co., Ltd.) }}\end{array}$ & $\begin{array}{l}\text { Composite cell product (allo- } \\
\text { geneic skin-derived keratino- } \\
\text { cytes suspended in a } \\
\text { thermosensitive hydrogel) for } \\
\text { deep 2nd degree burns }\end{array}$ & $\begin{array}{c}\text { Cell therapy } \\
\text { product }\end{array}$ & 16-Oct-2015 & Still in market & $\frac{\frac{\text { Click here for }}{\text { link to MFDS }}}{\underline{\text { website }}}$ \\
\hline $\begin{array}{r}\text { NEURONATA-R }{ }^{\circledR} \\
\text { (Corestem, Inc.) }^{\text {(Corem, }}\end{array}$ & $\begin{array}{l}\text { Autologous bone marrow mes- } \\
\text { enchymal stromal cell ther- } \\
\text { apy for Amyotrophic Lateral } \\
\text { Sclerosis }\end{array}$ & $\begin{array}{l}\text { Cell therapy } \\
\text { product }\end{array}$ & 30-Jul-2014 & Orphan product & $\frac{\frac{\text { Click here for }}{\text { link to MFDS }}}{\underline{\text { website }}}$ \\
\hline $\begin{array}{l}\text { Cupistem }^{\circledR} \\
\quad \text { (Anterogen) }\end{array}$ & $\begin{array}{l}\text { Autologous adipose } \\
\text { tissue-derived mesenchymal } \\
\text { stromal cell for Crohn's fistula }\end{array}$ & $\begin{array}{c}\text { Cell therapy } \\
\text { product }\end{array}$ & 18-Jan-2012 & $\begin{array}{l}\text { Covered by } \\
\text { insurance as of } \\
\text { Jan-2014, } \\
\text { orphan } \\
\text { product }\end{array}$ & $\frac{\frac{\text { Click here for }}{\text { link to MFDS }}}{\underline{\text { website }}}$ \\
\hline $\begin{array}{l}\text { CARTISTEM }^{\circledR} \\
\text { (Medipost Co., } \\
\text { Ltd.) }\end{array}$ & $\begin{array}{l}\text { Human umbilical cord blood- } \\
\text { - derived mesenchymal stro- } \\
\text { mal cells for the treatment of } \\
\text { knee articular cartilage } \\
\text { defects in patients with oste- } \\
\text { oarthritis (ICRS grade IV) }\end{array}$ & $\begin{array}{l}\text { Cell therapy } \\
\text { product }\end{array}$ & 18-Jan-2012 & Still in market & $\frac{\frac{\text { Click here for }}{\text { link to MFDS }}}{\underline{\text { website }}}$ \\
\hline
\end{tabular}


Table IX. (Continued).

\begin{tabular}{|c|c|c|c|c|c|}
\hline Name (MA holder) & $\begin{array}{l}\text { Product description and } \\
\text { indication }(\mathrm{s})\end{array}$ & Product category & Date of MA & Current status & $\begin{array}{l}\text { Additional } \\
\text { information }\end{array}$ \\
\hline $\begin{array}{l}\text { Cellgram }^{\circledR} \text {-AMI } \\
\text { (Pharmicell Co., } \\
\text { Ltd.) }\end{array}$ & $\begin{array}{l}\text { Autologous bone } \\
\text { barrow-derived mesenchymal } \\
\text { stromal cells for acute myocar- } \\
\text { dial infarction patients } \\
\text { (improvement of LVEF) }\end{array}$ & $\begin{array}{l}\text { Cell therapy } \\
\text { product }\end{array}$ & 1-Jul-2011 & $\begin{array}{l}\text { Name at time of } \\
\text { approval was } \\
\text { Heart- } \\
\text { icellgram }{ }^{\circledR}- \\
\text { AMI, } \\
\text { still in market }\end{array}$ & $\frac{\frac{\text { Click here for }}{\text { link to MFDS }}}{\underline{\text { website }}}$ \\
\hline $\begin{array}{l}\text { CureSkin Inj. (S. } \\
\text { Biomedics Co., } \\
\text { Ltd.) }\end{array}$ & $\begin{array}{l}\text { Autologous dermal fibroblasts } \\
\text { (depressed acne scar) }\end{array}$ & $\begin{array}{l}\text { Cell therapy } \\
\text { product }\end{array}$ & 11-May-2010 & Still in market & $\frac{\frac{\text { Click here for }}{\text { link to MFDS }}}{\underline{\text { website }}}$ \\
\hline $\begin{array}{l}\text { Queencell }^{\circledR} \\
\text { (Anterogen) }\end{array}$ & $\begin{array}{l}\text { Autologous adipose tis- } \\
\text { sue-derived adipose cell by } \\
\text { minimal manipulation for } \\
\text { subcutaneous tissue defect }\end{array}$ & $\begin{array}{l}\text { Cell therapy } \\
\text { product }\end{array}$ & 26-Mar-2010 & Still in market & $\frac{\text { Click here for }}{\underline{\text { link to MFDS }}}$ \\
\hline $\begin{array}{c}\text { Kaloderm }^{\circledR} \text { (Tego } \\
\text { Science, Inc) }\end{array}$ & $\begin{array}{l}\text { Allogeneic keratinocytes (cell } \\
\text { sheet) for deep 2nd degree } \\
\text { burn or diabetic foot ulcer }\end{array}$ & $\begin{array}{l}\text { Tissue engi- } \\
\text { neered product }\end{array}$ & $\begin{array}{l}\text { 21-Mar-2005 (2nd } \\
\text { degree burn) 24-Jun- } \\
2010 \text { (Diabetic foot } \\
\text { ulcer) }\end{array}$ & Still in market & $\frac{\frac{\text { Click here for }}{\text { link to MFDS }}}{\underline{\text { website }}}$ \\
\hline $\begin{array}{l}\text { RMS OssronTM } \\
\text { (Sewon Cellon- } \\
\text { tech Co., Ltd.) }\end{array}$ & $\begin{array}{l}\text { Cultured autologous osteo- } \\
\text { blasts for focal bone forma- } \\
\text { tion, can be used with or } \\
\text { without fibrin glue }\end{array}$ & $\begin{array}{l}\text { Cell therapy } \\
\text { product }\end{array}$ & 26-Aug-2009 & Still in market & $\frac{\frac{\text { Click here for }}{\text { link to MFDS }}}{\underline{\text { website }}}$ \\
\hline $\begin{array}{l}\text { Immuncell-LC } \\
\text { (GC Cell Corp.) }\end{array}$ & $\begin{array}{l}\text { Autologous activated } \mathrm{T} \text { cell for } \\
\text { liver cancer (hepatocellular } \\
\text { carcinoma) }\end{array}$ & $\begin{array}{l}\text { Cell therapy } \\
\text { product }\end{array}$ & 6-Aug-2007 & $\begin{array}{l}\text { Currently in } \\
\text { market for } \\
\text { hepatocellular } \\
\text { carcinoma and } \\
\text { in clinical trials } \\
\text { for newly diag- } \\
\text { nosed glioblas- } \\
\text { toma (phase 3, } \\
\text { completed) } \\
\text { advanced pan- } \\
\text { creatic cancer } \\
\text { (phase 2, } \\
\text { completed) }\end{array}$ & $\frac{\frac{\text { Click here for }}{\text { link to MFDS }}}{\underline{\text { website }}}$ \\
\hline $\begin{array}{l}\text { CreaVax-RCC }^{\circledR} \\
\text { (JW CreaGene } \\
\text { Corporation) }\end{array}$ & $\begin{array}{l}\text { Autologous dendritic cells for } \\
\text { metastatic renal cell } \\
\text { carcinoma }\end{array}$ & $\begin{array}{l}\text { Cell therapy } \\
\text { product }\end{array}$ & 15-May-2007 & $\begin{array}{l}\text { Received tenta- } \\
\text { tive approval in } \\
2007 \text { and prod- } \\
\text { uct manufac- } \\
\text { ture license as } \\
\text { export product } \\
\text { in } 2013 \text { from } \\
\text { MFDS }\end{array}$ & $\frac{\frac{\text { Click here for }}{\text { link to MFDS }}}{\underline{\text { website }}}$ \\
\hline $\begin{array}{l}\text { KeraHeal }^{\circledR} \text { (Bio- } \\
\text { solution Co., } \\
\text { Ltd.) }\end{array}$ & $\begin{array}{l}\text { Autologous skin-derived kera- } \\
\text { tinocytes for deep } 2 \text { nd degree } \\
\text { burns that cover }>30 \% \text { of } \\
\text { TBSA and } 3 \text { rd degree burns } \\
\text { that cover }>10 \% \text { of TBSA }\end{array}$ & $\begin{array}{l}\text { Cell therapy } \\
\text { product }\end{array}$ & 3-May-2006 & Still in market & $\frac{\frac{\text { Click here for }}{\text { link to MFDS }}}{\underline{\text { website }}}$ \\
\hline $\begin{array}{l}\text { Holoderm }^{\circledR}(\text { Tego } \\
\text { Science, Inc) }\end{array}$ & $\begin{array}{l}\text { Autologous keratinocytes for } \\
\text { deep 2nd degree burns that } \\
\text { cover }>30 \% \text { of TBSA and } \\
\text { 3rd degree burns that cover } \\
>10 \% \text { of TBSA }\end{array}$ & $\begin{array}{l}\text { Tissue engi- } \\
\text { neered product }\end{array}$ & 10-Dec-2002 & $\begin{array}{l}\text { Still in market, } \\
\text { reimbursed by } \\
\text { insurance }\end{array}$ & $\frac{\frac{\text { Click here for }}{\text { link to MFDS }}}{\underline{\text { website }}}$ \\
\hline $\begin{array}{l}\text { ChondronTM } \\
\text { (Sewon Cellon- } \\
\text { tech Co., Ltd.) }\end{array}$ & $\begin{array}{l}\text { Cultured autologous chondro- } \\
\text { cytes for focal cartilage defect } \\
\text { of knee, can be used with or } \\
\text { without fibrin glue }\end{array}$ & $\begin{array}{l}\text { Cell therapy } \\
\text { product }\end{array}$ & 30-Jan-2001 & Still in market & $\frac{\frac{\text { Click here for }}{\text { link to MFDS }}}{\underline{\text { website }}}$ \\
\hline
\end{tabular}

MFDS, Ministry of Food and Drug Safety; ICRS, International Cartilage Regeneration \& Joint Preservation Society; LVEF, left ventricular ejection fraction; TBSA, Total Burn Surface Area. 
Table X. List of cell/tissue/gene products with MA in the United States by USFDA.

\begin{tabular}{|c|c|c|c|c|c|}
\hline Name (MA holder) & Product description and indication(s) & Product category & Date of MA & Current status & $\begin{array}{l}\text { Additional } \\
\text { information }\end{array}$ \\
\hline $\begin{array}{l}\text { HPC, Cord Blood } \\
\text { (MD Anderson } \\
\text { Cord Blood Bank) }\end{array}$ & $\begin{array}{l}\text { For use in unrelated donor hematopoietic } \\
\text { progenitor cell transplantation proce- } \\
\text { dures in conjunction with an appropri- } \\
\text { ate preparative regimen for } \\
\text { hematopoietic and immunologic recon- } \\
\text { stitution in patients with disorders } \\
\text { affecting the hematopoietic system that } \\
\text { are inherited, acquired or result from } \\
\text { myeloablative treatment }\end{array}$ & $\begin{array}{l}\text { Cell therapy } \\
\text { product }\end{array}$ & 06-Jun-2018 & Still in market & $\frac{\text { Click here for }}{\underline{\text { link to FDA }}}$ \\
\hline $\begin{array}{l}\text { LUXTURNA (voreti- } \\
\text { gene neparvovec- } \\
\text { rzyl) (Spark Thera- } \\
\text { peutics, Inc.) }\end{array}$ & $\begin{array}{l}\text { Adeno-associated virus vector-based gene } \\
\text { therapy indicated for the treatment of } \\
\text { patients with confirmed biallelic RPE65 } \\
\text { mutation-associated retinal dystrophy }\end{array}$ & $\begin{array}{l}\text { Gene therapy } \\
\text { product }\end{array}$ & 19-Dec-2017 & Still in market & $\frac{\frac{\text { Click here for }}{\text { link to FDA }}}{\underline{\text { website }}}$ \\
\hline $\begin{array}{l}\text { YESCARTA (axicab- } \\
\text { tagene ciloleucel) } \\
\text { (Kite Pharma, } \\
\text { Incorporated) }\end{array}$ & $\begin{array}{l}\text { A CD19-directed genetically modified } \\
\text { autologous T-cell immunotherapy indi- } \\
\text { cated for the treatment of adult patients } \\
\text { with relapsed or refractory large B-cell } \\
\text { lymphoma after two or more lines of } \\
\text { systemic therapy, including DLBCL } \\
\text { not otherwise specified, primary medi- } \\
\text { astinal large B-cell lymphoma, high- } \\
\text { grade B-cell lymphoma and DLBCL } \\
\text { arising from follicular lymphoma }\end{array}$ & $\begin{array}{l}\text { Gene therapy } \\
\text { product }\end{array}$ & $18-O c t-2017$ & Still in market & $\frac{\text { Click here for }}{\underline{\text { link to FDA }}}$ \\
\hline $\begin{array}{l}\text { KYMRIAH (tisagen- } \\
\text { lecleucel) (Novartis } \\
\text { Pharmaceuticals } \\
\text { Corporation) }\end{array}$ & $\begin{array}{l}\text { CD19-directed genetically modified } \\
\text { autologous T-cell immunotherapy indi- } \\
\text { cated for the treatment of patients up to } \\
25 \mathrm{y} \text { of age with B-cell precursor ALL } \\
\text { that is refractory or in second or later } \\
\text { relapse }\end{array}$ & $\begin{array}{l}\text { Gene therapy } \\
\text { product }\end{array}$ & 30-Aug-2017 & Still in market & $\frac{\text { Click here for }}{\underline{\text { link to FDA }}}$ \\
\hline $\begin{array}{r}\text { MACI (Vericel } \\
\text { Corporation) }\end{array}$ & $\begin{array}{l}\text { Autologous cultured chondrocytes on a } \\
\text { porcine collagen membrane for the } \\
\text { repair of single or multiple symptom- } \\
\text { atic, full-thickness cartilage defects of } \\
\text { the knee with or without bone involve- } \\
\text { ment in adults }\end{array}$ & $\begin{array}{l}\text { Tissue engi- } \\
\text { neered product }\end{array}$ & 13-Dec-2016 & Still in market & $\frac{\frac{\text { Click here for }}{\text { link to FDA }}}{\underline{\text { website }}}$ \\
\hline $\begin{array}{l}\text { Clevecord (HPC, } \\
\text { Cord Blood) } \\
\text { (Cleveland Cord } \\
\text { Blood Center) }\end{array}$ & $\begin{array}{l}\text { For use in unrelated donor hematopoietic } \\
\text { progenitor cell transplantation proce- } \\
\text { dures in conjunction with an appropri- } \\
\text { ate preparative regimen for } \\
\text { hematopoietic and immunologic recon- } \\
\text { stitution in patients with disorders } \\
\text { affecting the hematopoietic system that } \\
\text { are inherited, acquired or result from } \\
\text { myeloablative treatment }\end{array}$ & $\begin{array}{l}\text { Cell therapy } \\
\text { product }\end{array}$ & 1-Sep-2016 & Still in market & $\frac{\text { Click here for }}{\frac{\text { link to FDA }}{\text { website }}}$ \\
\hline $\begin{array}{l}\text { HPC, Cord Blood } \\
\text { (Bloodworks) }\end{array}$ & $\begin{array}{l}\text { For use in unrelated donor hematopoietic } \\
\text { progenitor cell transplantation proce- } \\
\text { dures in conjunction with an appropri- } \\
\text { ate preparative regimen for } \\
\text { hematopoietic and immunologic recon- } \\
\text { stitution in patients with disorders } \\
\text { affecting the hematopoietic system that } \\
\text { are inherited, acquired or result from } \\
\text { myeloablative treatment }\end{array}$ & $\begin{array}{l}\text { Cell therapy } \\
\text { product }\end{array}$ & 28-Jan-2016 & Still in market & $\frac{\frac{\text { Click here for }}{\text { link to FDA }}}{\underline{\text { website }}}$ \\
\hline $\begin{array}{l}\text { IMLYGIC (talimo- } \\
\text { gene laherparepvec) } \\
\text { (Amgen Inc.) }\end{array}$ & $\begin{array}{l}\text { Genetically modified oncolytic viral ther- } \\
\text { apy indicated for the local treatment of } \\
\text { unresectable cutaneous, subcutaneous } \\
\text { and nodal lesions in patients with mela- } \\
\text { noma recurrent after initial surgery }\end{array}$ & $\begin{array}{l}\text { Gene therapy } \\
\text { product }\end{array}$ & $27-O c t-2015$ & Still in market & $\frac{\frac{\text { Click here for }}{\text { link to FDA }}}{\underline{\text { website }}}$ \\
\hline $\begin{array}{l}\text { HPC, Cord Blood } \\
\text { (LifeSouth }\end{array}$ & $\begin{array}{l}\text { For use in unrelated donor hematopoietic } \\
\text { progenitor cell transplantation }\end{array}$ & $\begin{array}{l}\text { Cell therapy } \\
\text { product }\end{array}$ & 13-Jun-2013 & Still in market & \\
\hline
\end{tabular}


Table X. (Continued).

\begin{tabular}{|c|c|c|c|c|c|}
\hline Name (MA holder) & Product description and indication(s) & Product category & Date of MA & Current status & $\begin{array}{l}\text { Additional } \\
\text { information }\end{array}$ \\
\hline $\begin{array}{l}\text { Community Blood } \\
\text { Centers, Inc.) }\end{array}$ & $\begin{array}{l}\text { procedures in conjunction with an } \\
\text { appropriate preparative regimen for } \\
\text { hematopoietic and immunologic recon- } \\
\text { stitution in patients with disorders } \\
\text { affecting the hematopoietic system that } \\
\text { are inherited, acquired or result from } \\
\text { myeloablative treatment }\end{array}$ & & & & $\frac{\text { Click here for }}{\underline{\text { link to FDA }}}$ \\
\hline $\begin{array}{l}\text { ALLOCORD (SSM } \\
\text { Cardinal Glennon } \\
\text { Children's Medical } \\
\text { Center) }\end{array}$ & $\begin{array}{l}\text { For use in unrelated donor hematopoietic } \\
\text { progenitor cell transplantation proce- } \\
\text { dures in conjunction with an appropri- } \\
\text { ate preparative regimen for } \\
\text { hematopoietic and immunologic recon- } \\
\text { stitution in patients with disorders } \\
\text { affecting the hematopoietic system that } \\
\text { are inherited, acquired or result from } \\
\text { myeloablative treatment }\end{array}$ & $\begin{array}{c}\text { Cell therapy } \\
\text { product }\end{array}$ & 30-May-2013 & Still in market & $\frac{\text { Click here for }}{\underline{\text { link to FDA }}}$ \\
\hline $\begin{array}{l}\text { Ducord (HPC, Cord } \\
\text { Blood) (Duke Uni- } \\
\text { versity School of } \\
\text { Medicine) }\end{array}$ & $\begin{array}{l}\text { For use in unrelated donor hematopoietic } \\
\text { progenitor cell transplantation proce- } \\
\text { dures in conjunction with an appropri- } \\
\text { ate preparative regimen for } \\
\text { hematopoietic and immunologic recon- } \\
\text { stitution in patients with disorders } \\
\text { affecting the hematopoietic system that } \\
\text { are inherited, acquired or result from } \\
\text { myeloablative treatment }\end{array}$ & $\begin{array}{l}\text { Cell therapy } \\
\text { product }\end{array}$ & 4-Oct-2012 & Still in market & $\frac{\text { Click here for }}{\underline{\text { link to FDA }}}$ \\
\hline $\begin{array}{l}\text { HPC, Cord Blood } \\
\text { (Clinimmune Labs, } \\
\text { University of Colo- } \\
\text { rado Cord Blood } \\
\text { Bank) }\end{array}$ & $\begin{array}{l}\text { For use in unrelated donor hematopoietic } \\
\text { progenitor cell transplantation proce- } \\
\text { dures in conjunction with an appropri- } \\
\text { ate preparative regimen for } \\
\text { hematopoietic and immunologic recon- } \\
\text { stitution in patients with disorders } \\
\text { affecting the hematopoietic system that } \\
\text { are inherited, acquired or result from } \\
\text { myeloablative treatment }\end{array}$ & $\begin{array}{l}\text { Cell therapy } \\
\text { product }\end{array}$ & 24-May-2012 & Still in market & $\frac{\text { Click here for }}{\underline{\text { link to FDA }}}$ \\
\hline $\begin{array}{l}\text { GINTUIT (Organo- } \\
\text { genesis, Inc.) }\end{array}$ & $\begin{array}{l}\text { Allogeneic cultured keratinocytes and } \\
\text { fibroblasts in bovine collagen (cellular } \\
\text { sheets) for topical (non-submerged) } \\
\text { application to a surgically created vas- } \\
\text { cular wound bed in the treatment of } \\
\text { mucogingival conditions in adults }\end{array}$ & $\begin{array}{l}\text { Tissue engi- } \\
\text { neered product }\end{array}$ & 9-Mar-2012 & Still in market & $\frac{\text { Click here for }}{\underline{\text { link to FDA }}}$ \\
\hline $\begin{array}{l}\text { Hemacord (HPC, } \\
\text { Cord Blood) (New } \\
\text { York Blood Center, } \\
\text { Inc.) }\end{array}$ & $\begin{array}{l}\text { For use in unrelated donor hematopoietic } \\
\text { progenitor cell transplantation proce- } \\
\text { dures in conjunction with an appropri- } \\
\text { ate preparative regimen for } \\
\text { hematopoietic and immunologic recon- } \\
\text { stitution in patients with disorders } \\
\text { affecting the hematopoietic system that } \\
\text { are inherited, acquired or result from } \\
\text { myeloablative treatment }\end{array}$ & $\begin{array}{l}\text { Cell therapy } \\
\text { product }\end{array}$ & $1-$ Nov-2011 & Still in market & $\frac{\text { Click here for }}{\underline{\text { link to FDA }}}$ \\
\hline $\begin{array}{l}\text { Laviv }^{\circledR} \text { (Azficel-T) } \\
\text { (Fibrocell Technol- } \\
\text { ogies, Inc.) }\end{array}$ & $\begin{array}{l}\text { Autologous fibroblasts for improvement } \\
\text { of the appearance of moderate-to- } \\
\text { severe nasolabial fold wrinkles in adults }\end{array}$ & $\begin{array}{l}\text { Cell therapy } \\
\text { product }\end{array}$ & 21-Jun-2011 & Still in market & $\frac{\text { Click here for }}{\underline{\text { link to FDA }}}$ \\
\hline $\begin{array}{l}\text { PROVENGE (sipu- } \\
\text { leucel-T) (Den- } \\
\text { dreon Corporation) }\end{array}$ & $\begin{array}{l}\text { Autologous cellular immunotherapy indi- } \\
\text { cated for the treatment of asymptomatic } \\
\text { or minimally symptomatic metastatic } \\
\text { castrate-resistant (hormone refractory) } \\
\text { prostate cancer }\end{array}$ & $\begin{array}{l}\text { Cell therapy } \\
\text { product }\end{array}$ & 29-Apr-2010 & Still in market & $\frac{\text { Click here for }}{\underline{\text { link to FDA }}}$ \\
\hline
\end{tabular}




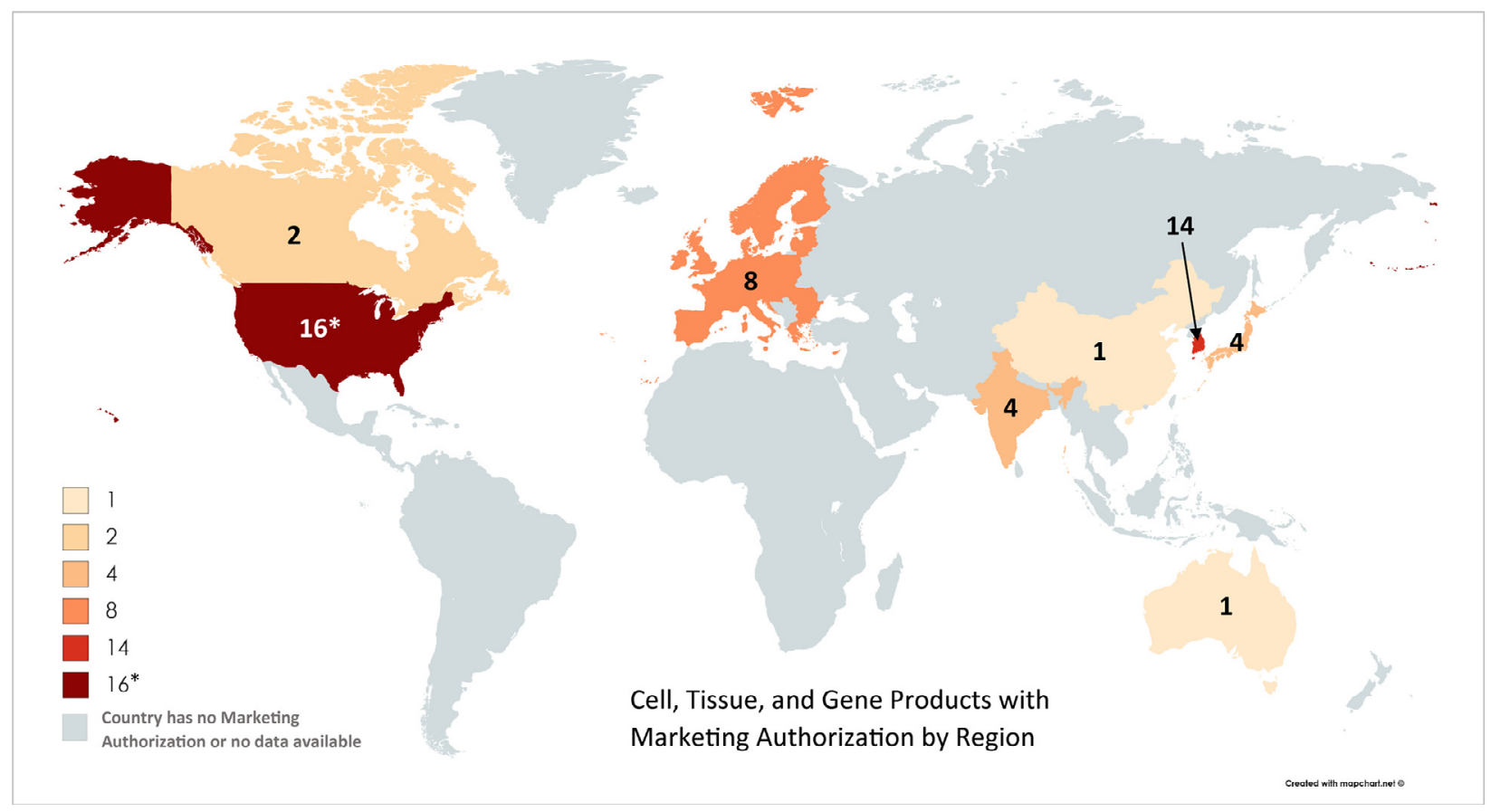

Figure 1. Number of cell, tissue and gene products with MA per region. ${ }^{\star}$ Eight products based on cord blood hematopoietic progenitors for unrelated donor hematopoietic progenitor cell transplantation have been included in the US's total number. These hold a MA license only in the US. Similar products are available in most countries as cell transplants and not as marketed products. The number of products presented in this figure does not include either products with Regenerative Medicine Advanced Therapy (RMAT) designation (United States Food and Drug Administration [USFDA]) or products with suspended MA.

Table XI. List of cell/tissue/gene products with RMAT Designation [4] in the United States by USFDA (Sep-2018).

\begin{tabular}{|c|c|c|c|c|c|}
\hline Name (MA holder) & $\begin{array}{l}\text { Product description and indication } \\
\text { (s) }\end{array}$ & Product category & $\begin{array}{l}\text { Date of RMAT } \\
\text { designation }\end{array}$ & $\begin{array}{l}\text { Additional } \\
\text { designations }\end{array}$ & $\begin{array}{l}\text { Additional } \\
\text { information }\end{array}$ \\
\hline $\begin{array}{l}\text { AT132 (Audentes } \\
\text { Therapeutics, Inc.) }\end{array}$ & $\begin{array}{l}\text { AAV-mediated gene therapy for } \\
\text { the treatment of XLMTM, a } \\
\text { rare monogenic disease caused } \\
\text { by mutations in the MTM1 gene }\end{array}$ & $\begin{array}{l}\text { Gene therapy } \\
\text { product }\end{array}$ & 21-Aug-2018 & $\begin{array}{l}\text { Rare pediatric } \\
\text { disease; fast } \\
\text { track; orphan } \\
\text { drug }\end{array}$ & Press release \\
\hline $\begin{array}{l}\text { Romyelocel-L } \\
\text { (Cellerant } \\
\text { Therapeutics, Inc.) }\end{array}$ & $\begin{array}{l}\text { Off-the-shelf human myeloid pro- } \\
\text { genitor cells for the prevention of } \\
\text { serious bacterial and fungal } \\
\text { infections in patients with de } \\
\text { novo AML undergoing induction } \\
\text { chemotherapy }\end{array}$ & $\begin{array}{l}\text { Cell therapy } \\
\text { product }\end{array}$ & 02-Jul-2018 & & $\underline{\text { Press release }}$ \\
\hline $\begin{array}{l}\text { VY-AADC (Voyager } \\
\text { Therapeutics, Inc.) }\end{array}$ & $\begin{array}{l}\text { AAV-mediated gene therapy for } \\
\text { the treatment of Parkinson's dis- } \\
\text { ease in patients with motor fluc- } \\
\text { tuations that are refractory to } \\
\text { medical management }\end{array}$ & $\begin{array}{l}\text { Gene therapy } \\
\text { product }\end{array}$ & 21-Jun-2018 & & Press release \\
\hline $\begin{array}{l}\text { CLBS14-RfA } \\
\text { (Caladrius } \\
\text { Biosciences, Inc.) }\end{array}$ & $\begin{array}{l}\text { CD34+ cell therapy program for } \\
\text { the treatment of refractory } \\
\text { angina }\end{array}$ & $\begin{array}{l}\text { Cell therapy } \\
\text { product }\end{array}$ & 19-Jun-2018 & & $\underline{\text { Press release }}$ \\
\hline $\begin{array}{l}\text { NSR-REP1 } \\
\text { (Nightstar } \\
\text { Therapeutics ple) }\end{array}$ & $\begin{array}{l}\text { AAV-mediated gene therapy for } \\
\text { the treatment of choroideremia, } \\
\text { a rare, degenerative, genetic reti- } \\
\text { nal disorder that leads to } \\
\text { blindness }\end{array}$ & $\begin{array}{l}\text { Gene therapy } \\
\text { product }\end{array}$ & 14-Jun-2018 & & $\underline{\text { Press release }}$ \\
\hline $\begin{array}{l}\text { ABO-102 (Abeona } \\
\text { Therapeutics Inc.) }\end{array}$ & $\begin{array}{l}\text { AAV-mediated gene therapy for } \\
\text { the treatment of Sanfilippo syn- }\end{array}$ & $\begin{array}{l}\text { Gene therapy } \\
\text { product }\end{array}$ & 23-Apr-2018 & & $\underline{\text { Press release }}$ \\
\hline
\end{tabular}
drome Type A (MPS IIIA), a rare autosomal-recessive lysosomal storage disease 
Table XI. (Continued).

\begin{tabular}{|c|c|c|c|c|c|}
\hline Name (MA holder) & $\begin{array}{l}\text { Product description and indication } \\
\text { (s) }\end{array}$ & Product category & $\begin{array}{l}\text { Date of RMAT } \\
\text { designation }\end{array}$ & $\begin{array}{l}\text { Additional } \\
\text { designations }\end{array}$ & $\begin{array}{l}\text { Additional } \\
\text { information }\end{array}$ \\
\hline $\begin{array}{l}\text { AmnioFix }^{\circledR} \\
(\text { MiMedx })\end{array}$ & $\begin{array}{l}\text { Allogeneic micronized dehydrated } \\
\text { human amnion/chorion mem- } \\
\text { brane for use in the treatment of } \\
\text { OA of the knee }\end{array}$ & $\begin{array}{l}\text { Tissue engi- } \\
\text { neered product }\end{array}$ & 9-Mar-2018 & & $\underline{\text { Press release }}$ \\
\hline $\begin{array}{l}\text { CAP-1002 (Capricor } \\
\text { Therapeutics) }\end{array}$ & $\begin{array}{l}\text { Allogeneic cell therapy (cardio- } \\
\text { sphere-derived cells) that is cur- } \\
\text { rently in clinical development for } \\
\text { the treatment of Duchenne mus- } \\
\text { cular dystrophy }\end{array}$ & $\begin{array}{l}\text { Cell therapy } \\
\text { product }\end{array}$ & 5-Feb-2018 & $\begin{array}{l}\text { Orphan drug; } \\
\text { rare pediatric } \\
\text { disease }\end{array}$ & $\underline{\text { Press release }}$ \\
\hline $\begin{array}{l}\text { EB-101 (Abeona } \\
\text { Therapeutics Inc.) }\end{array}$ & $\begin{array}{l}\text { Gene-corrected autologous cell } \\
\text { therapy product for patients with } \\
\text { RDEB }\end{array}$ & $\begin{array}{l}\text { Gene therapy } \\
\text { product }\end{array}$ & 29-Jan-2018 & $\begin{array}{l}\text { Breakthrough } \\
\text { therapy; } \\
\text { orphan drug; } \\
\text { rare pediatric } \\
\text { disease }\end{array}$ & $\underline{\text { Press release }}$ \\
\hline $\begin{array}{l}\text { MPC therapy (Meso- } \\
\text { blast Limited) }\end{array}$ & $\begin{array}{l}\text { MPC therapy in the treatment of } \\
\text { patients with heart failure with } \\
\text { left ventricular systolic dysfunc- } \\
\text { tion and LVADs }\end{array}$ & $\begin{array}{l}\text { Cell therapy } \\
\text { product }\end{array}$ & 21-Dec-2017 & & $\underline{\text { Press release }}$ \\
\hline $\begin{array}{l}\text { CEVA101 } \\
\text { (Cellvation) }\end{array}$ & $\begin{array}{l}\text { Autologous bone marrow-derived } \\
\text { stem cells for the treatment of } \\
\text { traumatic brain injury }\end{array}$ & $\begin{array}{l}\text { Cell therapy } \\
\text { product }\end{array}$ & 8-Nov-2017 & & $\underline{\text { Press release }}$ \\
\hline Multistem (Athersys) & $\begin{array}{l}\text { Proprietary stem cell product for } \\
\text { the treatment of ischemic stroke }\end{array}$ & $\begin{array}{l}\text { Cell therapy } \\
\text { product }\end{array}$ & 5-Oct-2017 & & $\underline{\text { Press release }}$ \\
\hline $\begin{array}{l}\text { AST-OPC1 (Asterias } \\
\text { Biotherapeutics) }\end{array}$ & $\begin{array}{l}\text { Oligodendrocyte progenitor cells } \\
\text { manufactured from pluripotent } \\
\text { embryonic stem cells for treat- } \\
\text { ment of patients with spinal cord } \\
\text { injury }\end{array}$ & $\begin{array}{l}\text { Cell therapy } \\
\text { product }\end{array}$ & 2-Oct-2017 & & $\underline{\text { Press release }}$ \\
\hline $\begin{array}{l}\text { LentiGlobin }^{\circledR} \text { BB305 } \\
\text { (Bluebird Bio) }\end{array}$ & $\begin{array}{l}\text { Ex vivo modified autologous } \\
\text { hematopoietic stem cells for } \\
\text { treatment of transfusion-depen- } \\
\text { dent } \beta \text {-thalassemia (also known } \\
\text { as } \beta \text {-thalassemia major) and } \\
\text { severe SCD }\end{array}$ & $\begin{array}{l}\text { Gene therapy } \\
\text { product }\end{array}$ & 1-Oct-2017 & & $\underline{\text { Press release }}$ \\
\hline $\begin{array}{l}\text { ATIR101 }^{\mathrm{TM}} \text { (Kiadis } \\
\text { Pharma) }\end{array}$ & $\begin{array}{l}\text { Adjunctive immunotherapeutic on } \\
\text { top of allogeneic HSCT }\end{array}$ & $\begin{array}{l}\text { Cell therapy } \\
\text { product }\end{array}$ & 20-Sep-2017 & & Press release \\
\hline $\begin{array}{l}\text { StrataGraft (Mal- } \\
\text { linckrodt ple) }\end{array}$ & $\begin{array}{l}\text { Autologous skin cell product for } \\
\text { the treatment of deep partial } \\
\text { thickness burns }\end{array}$ & $\begin{array}{l}\text { Tissue engi- } \\
\text { neered product }\end{array}$ & 18-Jul-2017 & & $\underline{\text { Press release }}$ \\
\hline $\begin{array}{l}\text { Ixmyelocel-T } \\
\text { (Vericel) }\end{array}$ & $\begin{array}{l}\text { Autologous expanded multicellu- } \\
\text { lar (mesenchymal cells, mono- } \\
\text { cytes and alternatively activated } \\
\text { macrophages) product for the } \\
\text { treatment of patients with } \\
\text { advanced heart failure due to } \\
\text { ischemic dilated cardiomyopathy }\end{array}$ & $\begin{array}{l}\text { Cell therapy } \\
\text { product }\end{array}$ & 10-May-2017 & & Press release \\
\hline jCell (jCyte) & $\begin{array}{l}\text { Adult retinal progenitor cells for } \\
\text { the treatment of } R P\end{array}$ & $\begin{array}{l}\text { Cell therapy } \\
\text { product }\end{array}$ & 2-May-2017 & & $\underline{\text { Press release }}$ \\
\hline RVT-802 (Enzyvant) & $\begin{array}{l}\text { Allogeneic thymic tissue for the } \\
\text { treatment of primary immune } \\
\text { deficiency resulting from cDGS }\end{array}$ & $\begin{array}{l}\text { Cell therapy } \\
\text { product }\end{array}$ & 17-Apr-2017 & $\begin{array}{l}\text { Breakthrough } \\
\text { therapy, rare } \\
\text { pediatric dis- } \\
\text { ease, orphan } \\
\text { drug }\end{array}$ & Press release \\
\hline $\begin{array}{l}\text { HUMACYL }^{\circledR} \\
\text { (Humacyte) }^{\text {(Humacte }}\end{array}$ & $\begin{array}{l}\text { HAV for patients undergoing } \\
\text { hemodialysis }\end{array}$ & $\begin{array}{l}\text { Tissue engi- } \\
\text { neered product }\end{array}$ & 20-Mar-2017 & & $\underline{\text { Press release }}$ \\
\hline $\begin{array}{l}\text { JCAR017 (Juno } \\
\text { Therapeutics) }\end{array}$ & $\begin{array}{l}\text { Treatment of } r / r \text { aggressive large } \\
\text { B-cell non-Hodgkin lymphoma }\end{array}$ & $\begin{array}{l}\text { Cell therapy } \\
\text { product }\end{array}$ & & & \\
\hline
\end{tabular}

AAV, adeno-associated virus; XLMTM, X-linked Myotubular Myopathy; AML, acute myeloid leukemia; OA, osteoarthritis; RDEB, recessive dystrophic epidermolysis bullosa; MPC, mesenchymal precursor cell; LVADs, left ventricular assist devices; SCD, sickle cell disease; HSCT, hematopoietic stem cell transplantation; RP, retinitis pigmentosa; cDGS, complete diGeorge Syndrome; HAV, human acellular vessel. 
A Product type

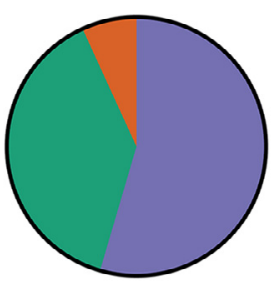

- 17 Allogeneic

- 24 Autologous

3 Gene Vector

C

\section{Disease Type}

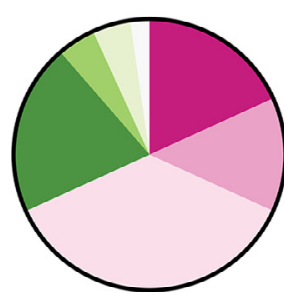

\section{B Therapy Type}

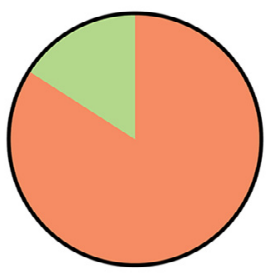

- 7 Gene Therapy

- 37 Cell Therapy
- 8 Skeletal Diseases

$6 \mathrm{Immunology}$ (GVHD included)

16 Oncology/Hematology

9 Skin/Mucosal/Soft-Tissue Diseases

2 Eye Diseases

2 Cardio Vascular Diseases

1 Neurological Diseases

Figure 2. Cell, tissue and gene products with MA worldwide (44 unique products) organized by (A) product type, (B) therapy type and (C) disease type. "Cell Therapy" products in (B) also include tissue engineered products. Eight products based on cord blood hematopoietic progenitors for unrelated donor hematopoietic progenitor cell transplantation have been included in the total number. These hold a MA license only in the US. Similar products are available in most countries as cell transplants and not as marketed products. The number of products presented in this figure does not include either products with RMAT designation (USFDA) or products with suspended MA. GVHD, graft-versus-host disease.

\section{Number of Cell/Tissue/Gene products with MA worldwide per year}

7

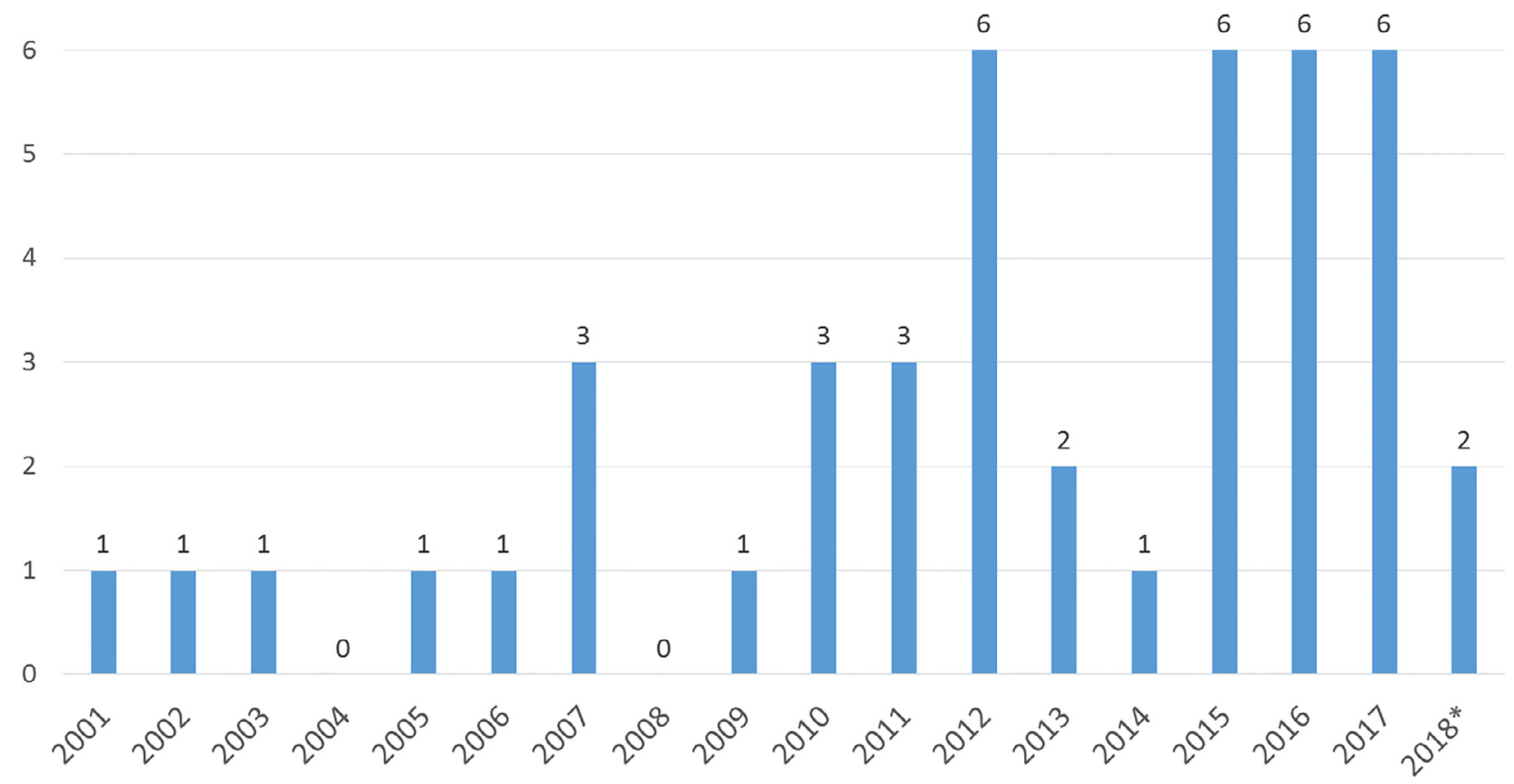

Figure 3. Cell, tissue and gene products with MA worldwide (44 unique products) organized by year of MA. Eight products based on cord blood hematopoietic progenitors for unrelated donor hematopoietic progenitor cell transplantation have been included in the total number. These hold a MA license only in the US. Similar products are available in most countries as cell transplants and not as marketed products. The number of products presented in this figure does not include either products with RMAT designation (USFDA) or products with suspended MA. 
completing the project. We are grateful to Doug Sipp (RIKEN, Kobe, Japan) for his help with MA status of cell, gene and tissue products in East Asia.

\section{References}

[1] Dominici M, Nichols K, Srivastava A, Weiss DJ, Eldridge P, Cuende N, et al. Positioning a Scientific Community on Unproven Cellular Therapies: The 2015 International Society for Cellular Therapy Perspective. Cytotherapy 2015;17:1663-6.
[2] Srivastava A, Mason C, Wagena E, Cuende N, Weiss DJ, Horwitz EM, et al. Part 1: Defining unproven cellular therapies. Cytotherapy 2016;18:117-9.

[3] Cuende N, Izeta A. Clinical translation of stem cell therapies: a bridgeable gap. Cell Stem Cell 2010;6:508-12.

[4] Marks P, Gottlieb S. Balancing safety and innovation for cellbased regenerative medicine. N Engl J Med 2018;378:954-9.

[5] Berger I, Ahmad A, Bansal A, Kapoor T, Sipp D, Rasko JEJ. Global distribution of businesses marketing stem cell-based interventions. Cell Stem Cell 2016;19:158-62.

[6] Knoepfler PS, Turner LG. The FDA and the US directto-consumer marketplace for stem cell interventions: a temporal analysis. Regen Med 2018;13:19-27. 